\section{STABILITY OF URANIUM SILICIDES DURING HIGH ENERGY ION IRRADIATION}

\author{
R. C. Birtcher and L. M. Wang* \\ Argonne National Laboratory \\ Argonne, Il 60439 \\ University of New Mexico \\ Electron Microscopy Laboratory, \\ Department of Geology \\ Albuquerque, NM 87131
}

$\mathrm{ANL} / \mathrm{CP}--73624$

DE92 005239

November 1991

The submitted manuscript has been authored

by a contractor of the U.S. Sovernment under contract No. W-31-109-ENG-38. Accordingly, the U.S. Government retains a nonexclusive. royaky-tree license to publish of reproduce the published form of this contribution, or allow others to do so. for U.S. Government purposes.

\title{
DISCLAIMER
}

\begin{abstract}
This report was prepared as an account of work spon. ,red by an agency of the 'inited States Government. Neither the United States Government nor any agency thereof, tor any of their employees, makes any warranty, express or implied, or assumes any legal 'iability or responsibility for the accuracy, completeness, or usefulness of any information, apparatus, product, or process disclosed, or represents that its use would not infringe privately owned rights. Reference herein to any specific commercial product, process, or service by trade name, trademark, manufacturer, or otherwise does not necessarily constitute or imply its endorsement, recommendation, or favoring by the United States Government or any agency thereof. The views and opinions of authors expressed herein do not necessarily state or reflect those of the United States Guvernment or any agency thereof.
\end{abstract}

Submitted to the Materials Research Society 1991 Fall Meeting, Dec. 2-6, 1991, Boston, MA.

*Wnrk supported by the U. S. Department of Energy, BES-Materials Sciences, under Cor - sact W-31-109-Eng-38 and the NSF. 


\title{
STABLITY OF URANIUM SILICIDES DURING HIGH ENERGY ION IRRADIATION
}

\author{
R. C. BIRTCHER AND L. M. WANG*, Argonne National Laboratory, 9700 South Cass \\ Avenue, Argonne, IL 60439. \\ *Present address: Electron Microscopy Laboratory, Department of Geology, University of New \\ Mexico, Albuquerque, NM 87131
}

\section{ABSTRACT}

Changes induced by $1.5 \mathrm{MeV} \mathrm{Kr}$ ion irradiation of both $\mathrm{U}_{3} \mathrm{Si}$ and $\mathrm{U}_{3} \mathrm{Si}_{2}$ have been followed by in situ transmission electron microcopy. When irradiated at sufficiently low temperatures, both alloys transform from the crystalline to the amorphous state. When irradiated at temperatures above the temperature limit for ion-beam amorphization, both compounds disorder, with the Martensite twin structure in U3Si disappearing from view in TEM. Prolonged irradiation of the disordered crystalline phases results in nucleation of small crystallites within the initially large crystal grains. The new crystallites increase in number during continued irradiation until a fine grain structure is formed. Electron diffraction yields a powder-like diffraction pattern that indicates a random alignment of the small crystallites. During a second irradiation at lower temperatures, the small crystallizes retard amorphization. After $2 \mathrm{dpa}$ at high temperatures, the amorphization dose is increased by over twenty times compared to that of initially unirradiated material.

\section{INTRODUCTION}

The history of irradiation effects is replete with examples of unexpected new behaviors that alter apparently reasonable expectations for the response of materials to an irradiation environment. Such examples include void swelling and irradiation induced segregation. A recent example has arisen from the desire to use intermetallics Uranium silicides as reactor fuel. Uranium silicides are being considered for use as reactor fuels in both high power and low enrichment applications because they have the advantages of high Uranium density and good thermal properties. However, $U_{3} \mathrm{Si}$ and $U_{3} \mathrm{Si}_{2}$ were found to become amorphous under irradiation [1]. In general, during irradiation amorphous materials become mechanically unstable to rapid swelling by plastic flow [2]. Prolonged reactor or ion irradiation of the amorphous, $\mathrm{U}_{3} \mathrm{Si}$ results in gross mechanical deformation and swelling due to plastic flow $[1,3]$. The mechanisms responsible ior plastic flow of irradiated amorphous systems are unknown.

A second anomaly in this chemical system comes from reactor irradiations of $\mathrm{U}_{3} \mathrm{Si}_{2}$ which have yielded a strong nonlinear swelling behavior. This behavior has been modelled on the basis of a irradiation-induced reduction in the grain size [4]. The importance of the grain structure lies in its acting as a rapid path for fission gas diffusion and providing sites for gas precipitation and bubble growth. This rapid swelling behavior in $\mathrm{U}_{3} \mathrm{Si}_{2}$ began at a Uranium burn-up of about $10 \%$ or about 8000 dpa. Although this dose is not achievable by ion beam techniques, it is possible to investigate the preliminary stages at lower doses. The present experiment follows the changes in the crystals and microstructures of $\mathrm{U}_{3} \mathrm{Si}$ and $\mathrm{U}_{3} \mathrm{Si}_{2}$ produced by high energy ion irradiation at temperatures above the temperature limit for amorphization.

\section{EXPERIMENTAL}

Alloys of depleted uranium and Silicon were arc melted and heat treated at $1075 \mathrm{~K}$ for 72 hours. For $\mathrm{U}_{3} \mathrm{Si}$ this treatment produced Martensite phase material containing dispersed small $\mathrm{U}_{3} \mathrm{Si}_{2}$ precipitates. The $\mathrm{U}_{3} \mathrm{Si}_{2}$ alloy was single phase. The starting ingots were sliced into $400 \mu \mathrm{m}$ thick wafers, and disks $3 \mathrm{~mm}$ in diameter were core-drilled from the wafers. TEM specimens were produced by jet polishing to created a perforation [5].

Irradiations were performed with $1.5 \mathrm{MeV} \mathrm{Kr}{ }^{+}$ions at fluxes less than $2 \times 10^{12} \mathrm{Kr} \mathrm{cm}^{-2}$ $\mathrm{sec}^{-1}$. The average projected range of the $\mathrm{Kr}$ ions in both $\mathrm{U}_{3} \mathrm{Si}$ and $\mathrm{U}_{3} \mathrm{Si}_{2}$ is estimated from TRIM [6] calculations to be about $200 \mathrm{~nm}$. Based on TRIM calculations, a fluence of $1 \times 10^{16}$ Kricm produces about 25 dpa for a displacement threshold of $20 \mathrm{eV}$. Less than $1 \%$ of the $\mathrm{Kr}$ 
would stop in the TEM transparent areas of the specimens. Specimens were irradiated in situ in the High Voltage Electron Mictoscopy-Tandem Accelerator User Facility at Argonne National Laboratory [7] in a Gatan double-tilt heating stage. This facility permits simultaneous ion irradiation and TEM observation over a wide range of temperature. The HVEM was operated at $300 \mathrm{kV}$, below the threshold for production of visible damage by electrons (approximately $600 \mathrm{kV}$ ). The specimen normal was tilted 25 degrees away from the electron beam so that the ion beam was incident about 5 degrees from the specimen normal. Images of the specimen were recorded with the $\mathrm{Kr}$ beam interrupted but without moving the specimen. Amorphization was defined as disappearance of all spots in the electron diffraction pattern.

\section{RESULTS AND DISCUSSION}

The microstructure of our unirradiated $\mathrm{U}_{3} \mathrm{Si}$ consisted of large grains tens of $\mu \mathrm{ms}$ in size and showed a rib Martensite structure, Figure 1. The crystal structure was tetragonal [8]. Extensive studies have been made of the stability of $\mathrm{U}_{3} \mathrm{Si}$ against amorphization by $1.5 \mathrm{MeV} \mathrm{Kr}$ ions [1] and Uranium fission [8]. The upper temperature limit for amorphization is about $250^{\circ} \mathrm{C}$. At lower temperatures, a $\mathrm{Kr}$ dose of less than $10^{14} \mathrm{ions} / \mathrm{cm}^{2}$, or $0.2 \mathrm{dpa}$, was sufficient to fully amorphize $\mathrm{U}_{3} \mathrm{Si}$. During low temperature ion irradiation, the $\mathrm{U}_{3} \mathrm{Si}$ chemically disordered, as seen by the loss of super lattice reflection in electron diffraction, and the Martensite structure disappeared from the TEM images. A detail neutron diffraction study was made of the crystallographic changes preceding amorphization induced by Uranium fission produced by neutron bombardment at room temperature [8]. Amorphization was preceded by a transformation from the tetragonal Martensite phase to the high temperature cubic phase. In spite of the localized nature of the cascade damage, this transformation was homogeneous through the material.

The response of $\mathrm{U}_{3} \mathrm{Si}$ to $1.5 \mathrm{MeV} \mathrm{Kr}$ ion irradiation at temperatures above the temperature limit for amorphization is shown by TEM images and electron diffraction patterns in Figures. 1 and 2. The atomically ordered Martensite crystal grains are visible as parallel platelets, and the diffraction shows the ordered tetragonal crystal structure.
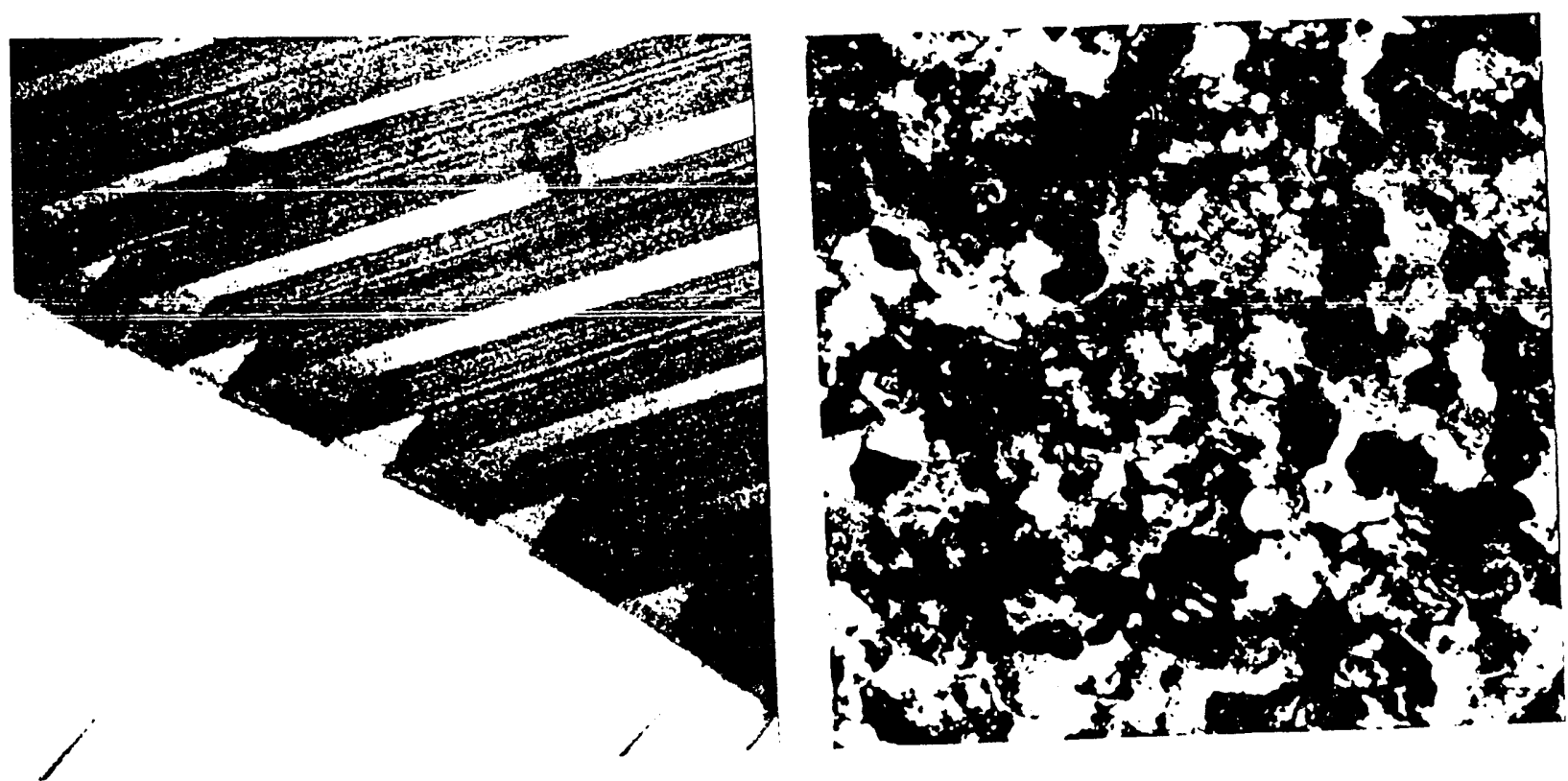

Figure 1. TEM images of $\mathrm{U}_{3} \mathrm{Si}$ before and after irradiation with $1.5 \mathrm{MeV} \mathrm{Kr}$ ions to a dose of $8 \cdot 10^{15}$ ions $/ \mathrm{cm}^{2}$ at $350^{\circ} \mathrm{C}$.

I) uring irradiation at $350^{\circ} \mathrm{C}$, the Martensite structure disordered to the point that it disappeared from the TEM image after a dose of $5 \cdot 10^{13}$ ions $/ \mathrm{cm}^{2}$. The disordered structure was replaced by small cirystal grains having sizes on the order of 100 to $200 \AA^{\prime}$ at doses greater than $10^{15} \mathrm{ions} / \mathrm{cm}^{2}$. 
During the course of irradiation the small grains increased in number and appear to increase very slowly in size. Due to the complex overlapping microstructure this last point remains incertain. The crystallographic transformation is illustrated in Figure 2 by a series of diffraction patterns taken at different doses during interruptions of the $\mathrm{Kr}$ irradiation.

Unirradiated

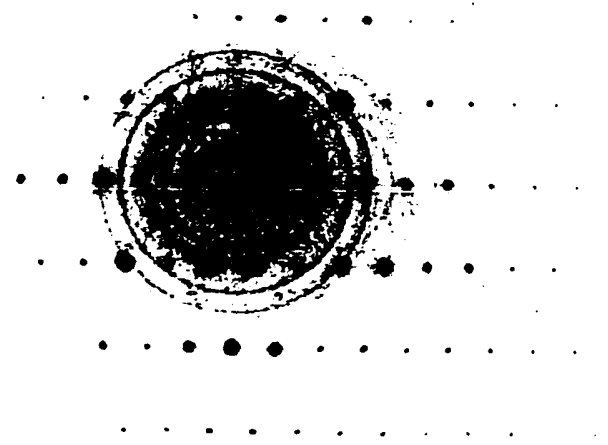

$1.5 \cdot 10^{15}$ ions $/ \mathrm{cm}^{2}$

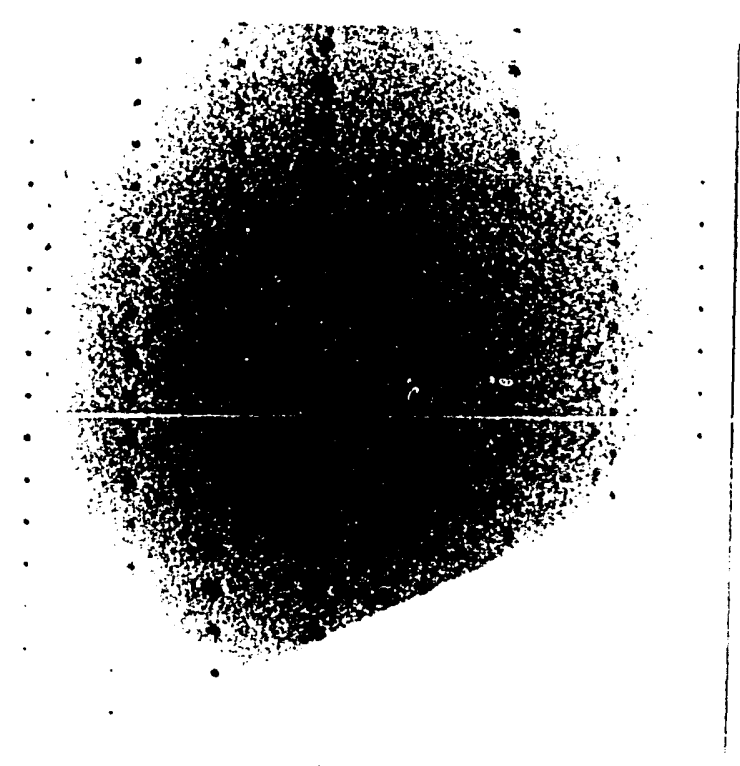

$0.6 \cdot 10^{15}$ ions $/ \mathrm{cm}^{2}$

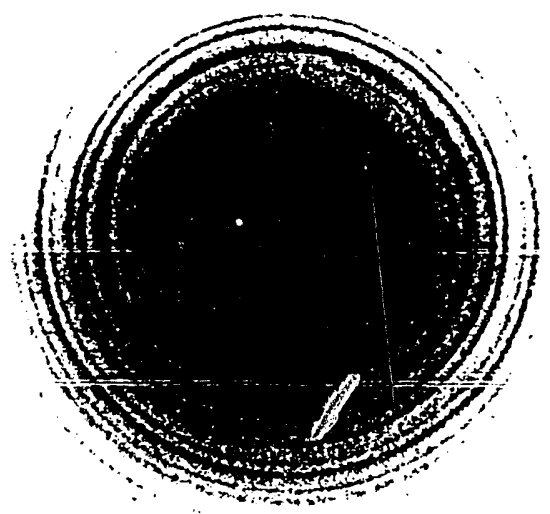

$3.0 \cdot 10^{15}$ ions $/ \mathrm{cm}^{2}$

Figure 2. Electron diffraction from $\mathrm{U}_{3} \mathrm{Si}$ irradiated with $1.5 \mathrm{MeV} \mathrm{Kr}$ ion to dose of $0 ; 0.6$; 1.5 and $3.0 \cdot 10^{15}$ ions $/ \mathrm{cm}^{2}$

Deterioration of the initial crystalline diffraction was concurrent with the polynanochotomization . Complete removal of the initial crystal structure occurs by a dose of $3 \cdot 10^{15}$ ions $/ \mathrm{cm}^{2}$ or about 3.5 $\mathrm{dpa}$, and the resultant diffraction pattern corresponds to that of powder cubic U3Si which is the high temperature parent phase. This crystallographic transformation sequence differs in several fundamental ways from the changes preceding amorphization found during room temperature neutron irradiation of $\mathrm{U}_{3} \mathrm{Si}$. Fission fragment damage at room temperature homogeneously 
distorted the $\mathrm{U}_{3} \mathrm{Si}$ crystal structure from the tetragonal phase toward the cubic phase without the coexistence of the initial and final crystalline phases. After transformation, the defected cubic phase was unstable and amorphized. During high-temperature ion irradiation the localized damage events transformed finite size volumes of material, and the two phases coexisted together. Because of limited microscope resolution, it has not been possible to determine whether a single ion tract is capable of directly converting a small volume of either the tetragonal or disordered crystal to the cubic phase. While amorphization requires a fraction of a dpa, high temperature grain refinement is complete after $3 \cdot 10^{15}$ ions $/ \mathrm{cm}^{2}$ or $7.5 \mathrm{dpa}$. This is likely due to thermal annealing of the damage during the irradiation.
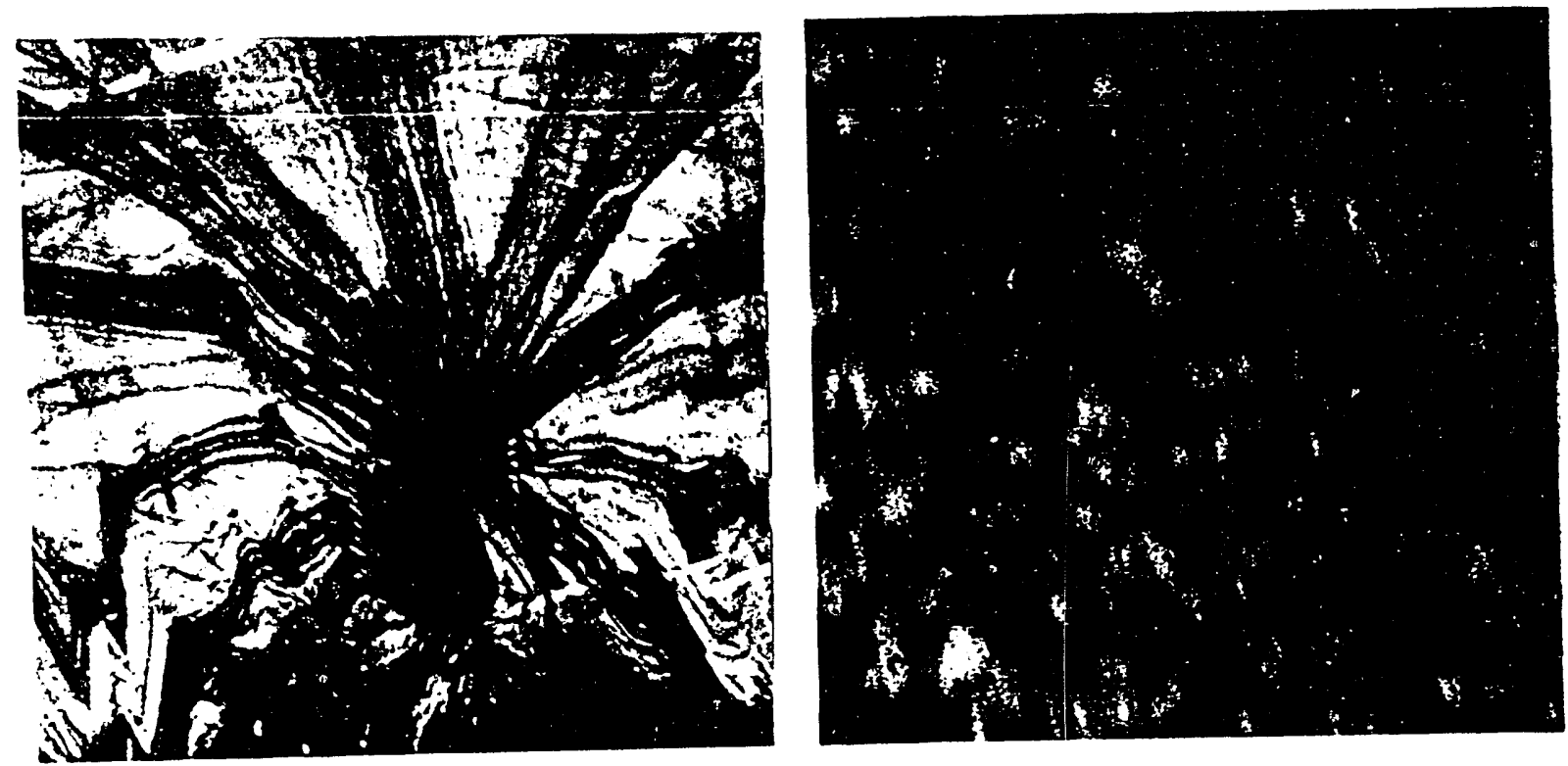

Figure 3. TEM images of $\mathrm{U}_{3} \mathrm{Si}_{2}$ before and after irradiation with $1.5 \mathrm{MeV} \mathrm{Kr}$ ions to a dose of $4 \cdot 10^{15}$ ions $/ \mathrm{cm}^{2}$ at $350^{\circ} \mathrm{C}$.

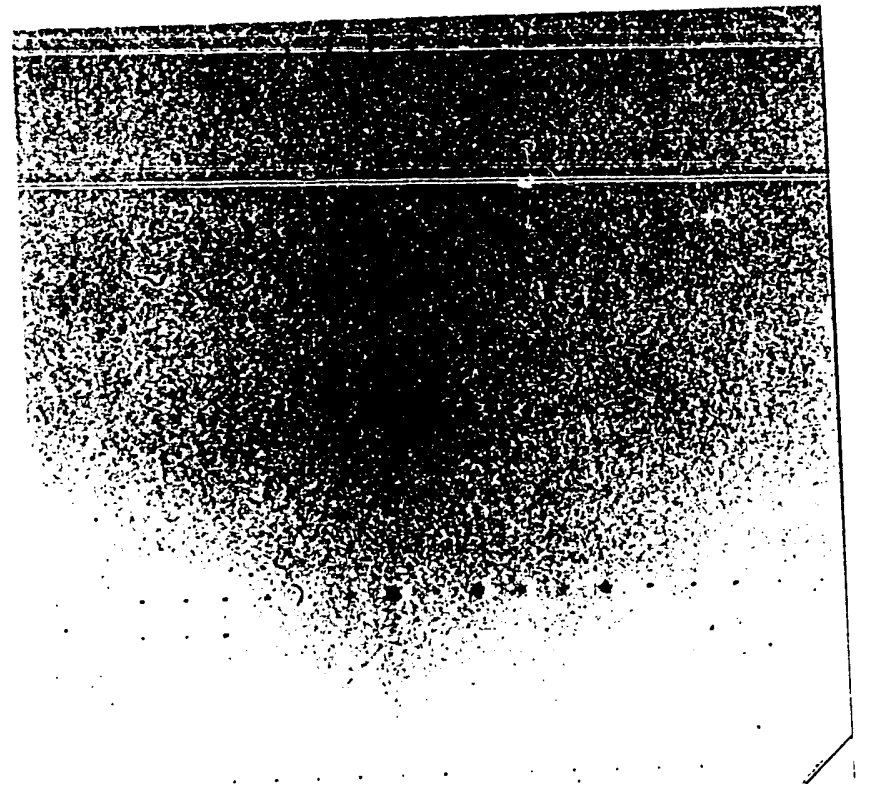

Unirradiated

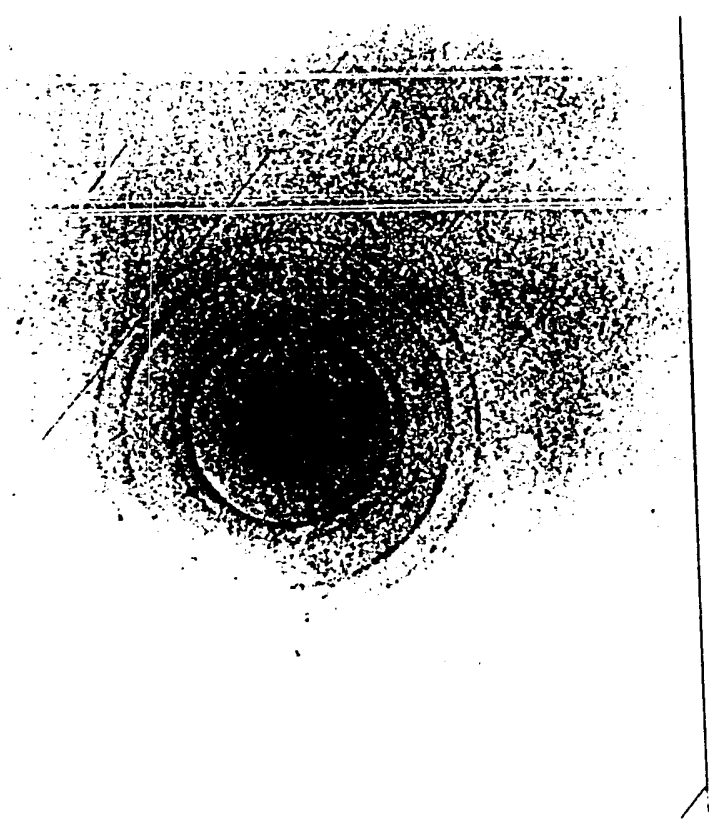

$4.0 \cdot 10^{15} \mathrm{ions} / \mathrm{cm}^{2}$

Figure 4. Electron diffraction from $\mathrm{U}_{3} \mathrm{Si}_{2}$ irradiated with $1.5 \mathrm{MeV} \mathrm{Kr}$ ion to dose of 0; 1.0 ; 2.0 and $4.0 \cdot 10^{15}$ ions $/ \mathrm{cm}^{2}$ 
The response of $\mathrm{U}_{3} \mathrm{Si}_{2}$ to $1.5 \mathrm{MeV} \mathrm{Kr}$ ion irradiation at temperatures above the temperature limit for amorphization is shown by TEM images and electron diffraction patterns in Figures. 3 and 4. Initially the $\mathrm{U}_{3} \mathrm{Si}_{2}$ consisted of atomically ordered crystalline grains with tetragonal crystal structure, and the TEM image showed only bend contours. During irradiation at $350^{\circ} \mathrm{C}$, the crystal structure disordered to the point that bend contours disappeared from the TEM image. The crystalline transformation is illustrated in Figure 5 by a series of diffraction patterns taken during interruptions of the $\mathrm{Kr}$ irradiation. Deterioration of the initial crystal structure was concurrent with formation of small grains, Figure $4 \mathrm{~b}$. These grains have sizes on the order of 100 to $200 \AA$ as was found for $\mathrm{U}_{3} \mathrm{Si}_{2}$. During irradiation, the small grains increased in number until they filled the specimen. Complete removal of the initial structure occured by a dose of $4 \cdot 10^{15}$ ions $/ \mathrm{cm}^{2}$.

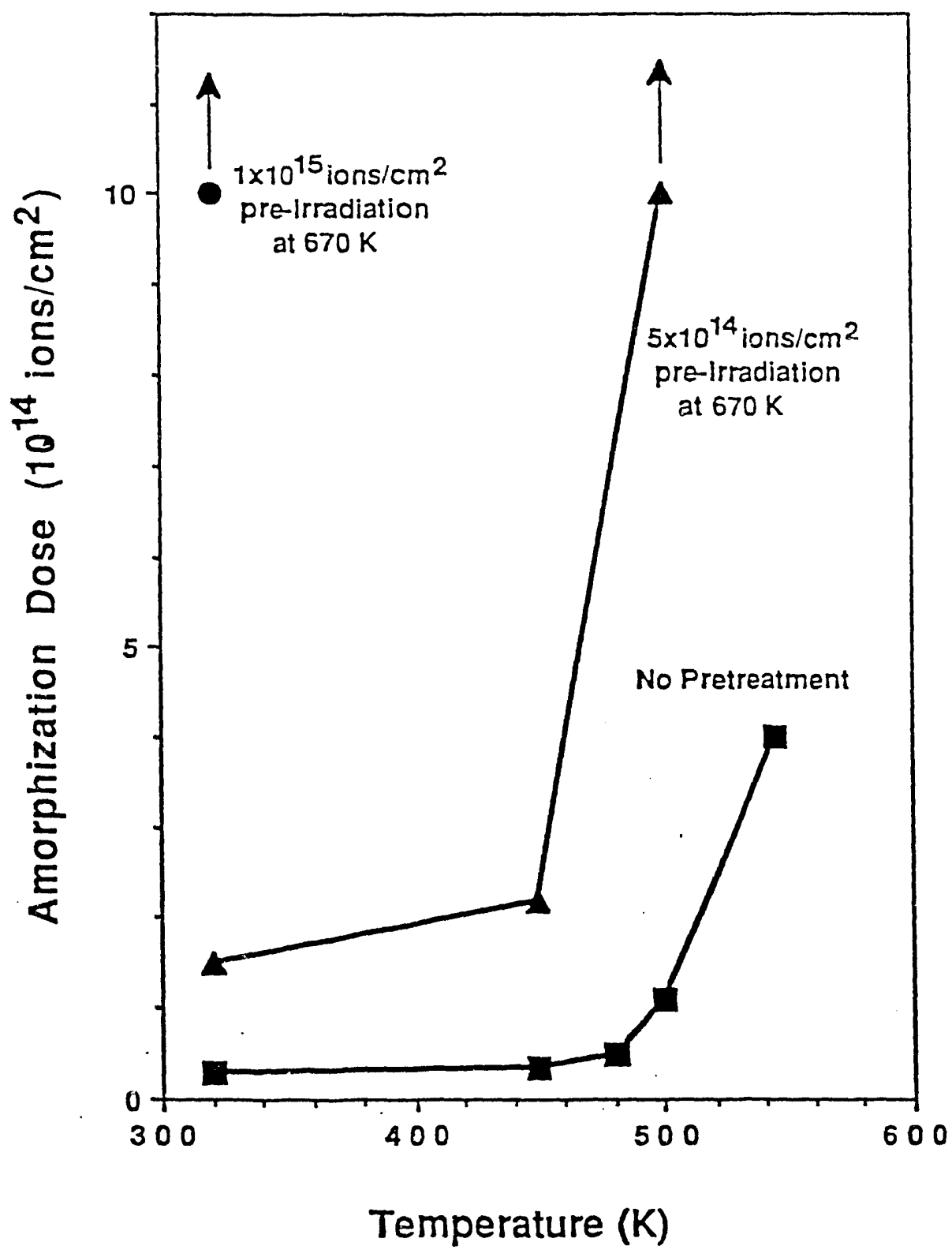

Figure 5. Temperature dependence of the dose of $1.5 \mathrm{MeV} \mathrm{Kr}$ ions required to amorphize $\mathrm{U}_{3} \mathrm{Si}$ with or without high-temperature irradiation treatments. 
Grain refinement has a strong affect on ion-beam amorphization. When grain refined $\mathrm{U}_{3} \mathrm{Si}$ or $\mathrm{U}_{3} \mathrm{Si}_{2}$ are irradiated at temperatures below the amorphization temperature limit, the ion dose required for amorphization is greatly increased. This effect is illustrated in Figure 5 for U3Si. The degree of increase in amorphization dose depends on the irradiation dose at high temperature or the amount of grain refinement. After a dose of $1.10^{15} \mathrm{ions} / \mathrm{cm}^{2}$ at $350^{\circ} \mathrm{C}$, complete amorphization was not observed during room temperature irradiation to a dose of $1.10^{15}$ ions $/ \mathrm{cm}^{2}$ or 20 times the normal amorphization dose.

There are several possible explanations for this observation. High density grain boundaries are expected tc act as an effective defect sink, and enhanced defect annihilation may be responsible for reiarding amorphization at room temperature. A second possible explanation involves the dynamic interaction of the defect cascade with grains on the order of cascade sizes. When a cascade forms, a volume of material is melted and quenched. It may be that with boundaries in close proximity on all side that the crystalline phase regrows and the amorphous phase does not form. A third possibility is that a crystal stiffening prevents the decrease in elastic modulus observed to precede amorphization [9].

\section{CONCLUSIONS}

Grain refinement has been observed for $\mathrm{U}_{3} \mathrm{Si}$ and $\mathrm{U}_{3} \mathrm{Si}_{2}$ irradiated at temperatures above their amorphization temperature limits. Their behaviors are quite similar to that observed for $\mathrm{Zr} 3 \mathrm{Al}$ [9]. $\mathrm{U}_{3} \mathrm{Si}_{2}$ was converted to fine grain polycrystal material at a dose $1 / 3$ greater than that required for $\mathrm{U}_{3} \mathrm{Si}$. The dose required to amorphize $\mathrm{U}_{3} \mathrm{Si}_{2}$ is also $1 / 3$ greater than that for $\mathrm{U}_{3} \mathrm{Si}$. The fact that these ion doses have the same ratio likely indicate that the same displacement processes are involved in the two materials and only the threshold energies differ. The conversion of tetragonal $\mathrm{U}_{3} \mathrm{Si}$ to the high temperature cubic phase by irradiation defects has a parallel to the high temperature phase transformation driven by the thermal vacancy concentration.

Grain refinement during irradiation has several important impacts on irradiation behavior. The first is the suppression of amorphization displayed in Figure 5. Because of plastic flow during irradiation of amorphous materials, any phenomenon that stabilizes a crystalline phase is important. In addition, understanding this effect should help elucidate the mechanism(s) for irradiation induced amorphization. It is not clear at this time if the suppression is due to enhanced defect annihilation at the additional grain boundaries or due to a crystal stiffening that prevents the decrease in elastic modulus observed to precede amorphization [9].

A second major impact is enhanced reactor-fuel swelling expected when fission gas is able to migrate to grain boundaries before being trapped. This more efficient gas collection may increase the swelling rate by a factor of ten [4]. Such grain refinement has been observed for $\mathrm{UO}_{2}$ and is suspected to playa major role in the swelling behavior of other reactor fuels.

\section{REFERENCES}

1 R. C. Birtcher, C. W. Allen, L. E. Rehn and G. L. Hofman, J. Nucl. Mater. 152, 73 (1988).

2 S. Klaumünzer and G, Schumacher, Phys. Rev. Lett. 51 (1983) 1987.

3 G. L. Hofman, J. Nucl. Mat. 140, 256 (1986).

4 J. Rest and G. L. Hofman, !5th Symposium on Effects of Radiation on Materials, Nashville, TN, 17-21 June 1990, ASM International

5 B. Kestel, Ultramicroscopy $25,91,1988$.

6 J. Biersack and L. G. Haggmark, Nuc!. Instr. and Meth. 174, 257 (1980).

7 A. Taylor, C. W. Allen and E. A. Ryan, Nucl. Inst. and Methods in Phys. Res. B24, $1987, \mathrm{p} 598$.

8 Okamoto,F.A. and Meshii,M., 1990, in Science of Advanced Materials, edited by H. Wiedersich and M. Meshii (ASM International).

9 R. C. Birtcher and L.M. Wang. Nucl. Instr. and Meth. B59/60, 966, 1991. 

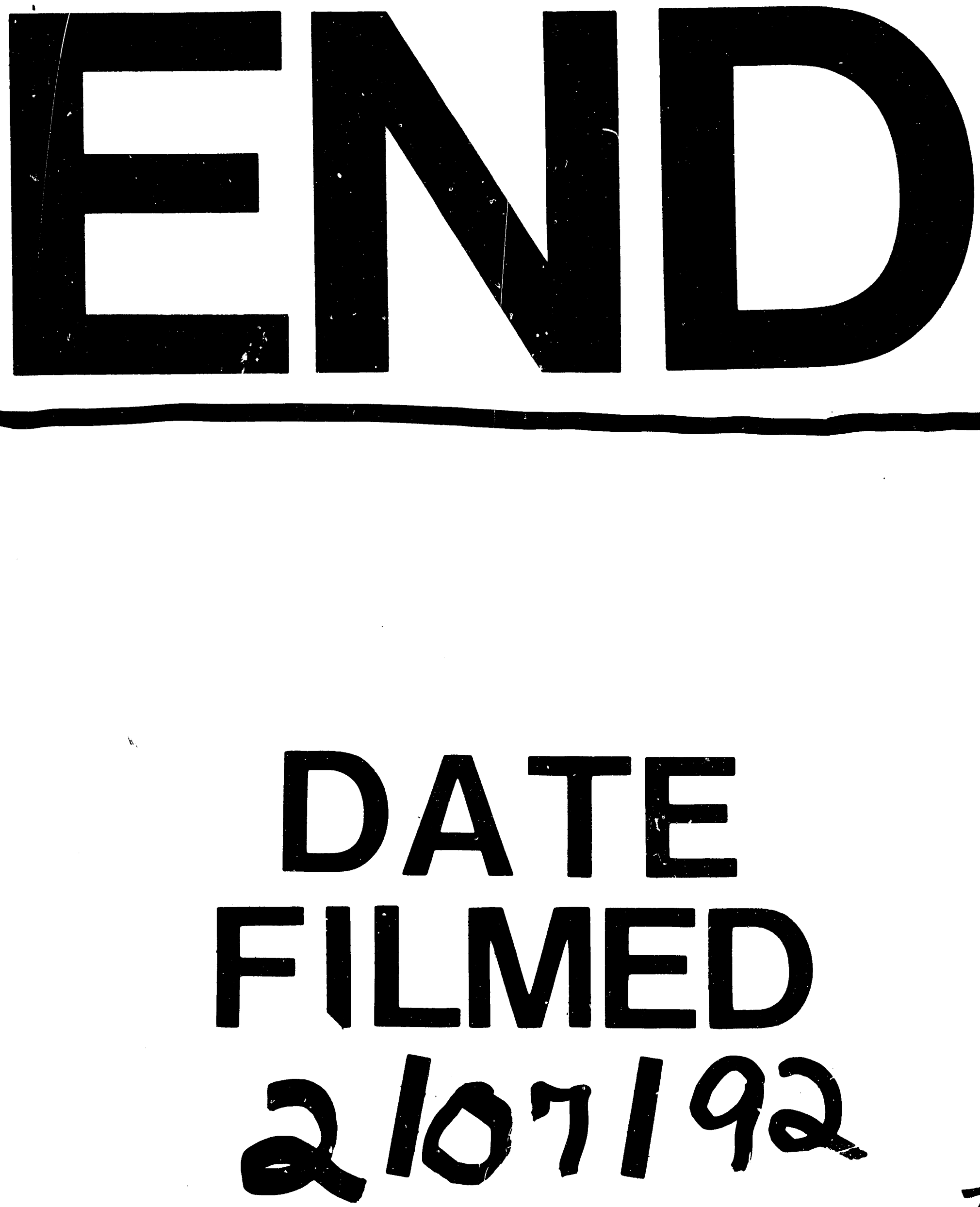

$I$ 
